NBER WORKING PAPER SERIES

\title{
THE SKILL COMPOSITION OF MIGRATION AND THE GENEROSITY OF THE WELFARE STATE
}

\author{
Alon Cohen \\ Assaf Razin \\ Efraim Sadka \\ Working Paper 14738 \\ http://www.nber.org/papers/w14738 \\ NATIONAL BUREAU OF ECONOMIC RESEARCH \\ 1050 Massachusetts Avenue \\ Cambridge, MA 02138 \\ February 2009
}

The views expressed herein are those of the author(s) and do not necessarily reflect the views of the National Bureau of Economic Research.

NBER working papers are circulated for discussion and comment purposes. They have not been peerreviewed or been subject to the review by the NBER Board of Directors that accompanies official NBER publications.

(C) 2009 by Alon Cohen, Assaf Razin, and Efraim Sadka. All rights reserved. Short sections of text, not to exceed two paragraphs, may be quoted without explicit permission provided that full credit, including (c) notice, is given to the source. 
The Skill Composition of Migration and the Generosity of the Welfare State Alon Cohen, Assaf Razin, and Efraim Sadka

NBER Working Paper No. 14738

February 2009

JEL No. F22,H55

\section{ABSTRACT}

Skilled migrants typically contribute to the welfare state more than they draw in benefits from it. The opposite holds for unskilled migrants. This suggests that a host country is likely to boost (respectively, curtail) its welfare system when absorbing high-skill (respectively, low-skill) migration. In this paper we first examine this hypothesis in a politico-economic setup. We then confront the prediction of the theory with evidence. In doing so, we reckon with an endogeneity problem that arise because the skill composition of migration is itself affected by the generosity of the welfare state.

Alon Cohen

Eitan Berglas School of Economics

Tel Aviv University, Tel Aviv 69978, Israel

alonc@post.tau.ac.il

Assaf Razin

Department of Economics

Cornell University

Uris 422

Ithaca, NY 14853

and NBER

ar256@cornell.edu
Efraim Sadka

Tel Aviv University

Eitan Berglas School of Economics

P.O.B. 39040

Ramat Aviv, Tel Aviv, 69978, ISRAEL

sadka@post.tau.ac.il 


\section{Introduction}

Skilled migrants typically contribute to the welfare state (in tax payments) more than they receive from it. The opposite is true in the case of unskilled migrants who typically impose a net fiscal burden on the welfare state. Indeed, in 1997 the U.S. National Research Council sponsored a study on the overall fiscal impact of immigration into the U.S.; see Smith and Edmonston (1997). The study looks carefully at all layers of government (federal, state, and local), all programs (benefits), and all types of taxes. The findings suggest that migrants with less than high school education are typically a net fiscal burden that can reach as high as approximately US\$100,000 in present value, when the migrants' age on arrival is between 20-30 years ${ }^{1}$. On the other hand, a young migrant, aged approximately 20 years on arrival, with more than high-school education, is expected to make a positive net fiscal contribution of approximately US\$300,000 in present value.

The aforementioned findings suggest that a host country is likely to boost its welfare system when absorbing high-skill migration, and curtail it when absorbing low-skill migration. ${ }^{2}$ Hence, as the skill composition of immigrants decreases, the fiscal leakage to the new comers increases (at the expense of the domestics). This may induce a reduction of the welfare-state expenditure. This is indeed the hypothesis that is studied in this paper (see also Razin, Sadka and Swagel (2002)).

We first develop a parsimonious model in which the extent of the welfare state is determined by majority voting. We then study how the skill composition of a given migration volume affects the politico-economic equi-

\footnotetext{
${ }^{1}$ See also Auerbach and Oreopoulos (1999) for a further analysis of these findings. Storesletten (2000) calibrated a general-equilibrium, overlapping generations model to capture the effects of inflows of working age immigrants to the U.S. on the fiscal system, taking into account changes in factor prices.

${ }^{2}$ For a recent comprehensive survey of the economic consequences of migration see Hanson (2008).
} 
librium level of the welfare state. Indeed, the parsimonious model confirms this hypothesis.

We then turn to study some evidence on the effect of migration on the generosity of the welfare state. In doing so we have to deal with some serious endogeneity problems. Note that the skill composition of migrants may indeed affect the generosity of welfare state, as our model suggests, but this generosity itself may affect the skill composition of migrants, as in Cohen and Razin (2008). To overcome this endogeneity problem, we adopt a twofold identification strategy. First, we employ instrumental variables that are commonly used in gravity models - whether or not the source and host country share a common language and the distance between them - for highand low-skill migration. Second, as shown in Cohen and Razin (2008), when estimating the effect of generosity of the welfare state on the skill composition of immigrants, one must account for different (source-host country pairs) migration regimes. Specifically, when migration is policy-controlled, the host country can react to low-skill dominated immigration pressures not only by curtailing welfare state benefits (as suggested herein) but also by controlling the skill composition of the immigrants, via screening migration policy or limiting access to some welfare benefits ${ }^{3}$. To capture the full effect of the skill composition of migrants on the welfare state, therefore, we focus only in a sample of countries that enable free migration among themselves, as well as equal treatment of the welfare system for domestic and migrants.

The organization of the paper is as follows. The next section describes the analytical framework. Section 3 provides the empirical evidence. Section

\footnotetext{
${ }^{3} \mathrm{EU}$ countries specifically favor their domestic and EU-originated migrants over nonEU-originated migrants - within the labor markets (Brucker et al. (2002). Possibly, denying welfare eligibility is also a possiblity to control migration (see Sinn (2004)) . In this case, a low composition of skills among immigrants, who may not be eligible to all welfare benefits, impose a much less burden upon the fiscal system of the host country. Hence the leakage is smaller, thus the expected reduction of the tax-welfare program is smaller, if at all.
} 
4 concludes.

\section{Analytical Framework}

We employ a parsimonious model of the welfare state, where migration is exogenous, whereas the extent of redistribution is determined in a politicoeconomic equilibrium. ${ }^{4}$ In particular, we consider the volume of migration, $\mu$, and its skill composition, $\sigma$, as the exogenous variables, and we let the native-born voters choose the tax rate, $\tau$; and, consequently, the generosity of the welfare state (the per-capita spending, $b) .{ }^{5}$ We then ask how an exogenous change in the skill composition of the migrants, $\sigma$, affect the chosen parameters of the welfare state, $\tau$ and $b$.

Assume a Cobb-Douglas production function, with two labor inputs, skilled and unskilled ${ }^{6}$ :

$$
Y=A L_{s}^{\alpha} L_{u}^{1-\alpha}, 0<\alpha<1
$$

where $Y$ is the GDP, $A$ denotes a Hicks-neutral productivity parameter, and $L_{i}$ denotes the input of skilled and unskilled labor $i$, where $i=\{s, u\}$.

The competitive wages of skilled and unskilled labor are given, respectively, by these marginal products:

$$
\begin{gathered}
w_{s}=\alpha Y / L_{s} \\
w_{u}=(1-\alpha) Y / L_{u}
\end{gathered}
$$

Aggregate labor supplies of skilled and unskilled workers, respectively,

\footnotetext{
${ }^{4}$ This model was first employed in Cohen and Razin (2008).

${ }^{5}$ This setup differs from the one employed in Razin, Sadka and Swagel (2002) in two main features: First, considers both skilled and unskilled migrants; Second, it allows migration to affect wages.

${ }^{6}$ This parsimonious model is developed with the cross-section data is mind. The migration variable is the stock of migrants; not flows (as relevant for dynamic analysis).
} 
are given by:

$$
\begin{gathered}
L_{s}=(s+\sigma \mu) l_{s} \\
L_{u}=(1-s+(1-\sigma) \mu) l_{u}
\end{gathered}
$$

There is a continuum of workers, where the number of native born is normalized to $1 ; s$ denotes the share of native born skilled in the total native born labor supply; $\sigma$ denotes the share of skilled migrants in the total number of migrants; $\mu$ denotes the total number of migrants; and $l_{i}$ is the labor supply of an individual with skill-level $i$.

Total population (native born and immigrants) is:

$$
N=1+\mu
$$

We specify a simple welfare-state system which levies a proportional labor income tax of the rate $\tau$, with the revenues are spent equally on all residents (native born and migrants alike) in the form of public services such as education, health, etc., that are distributed to all workers, regardless of their contribution to the tax revenues.

The government budget constraint is:

$$
N b=\tau Y
$$

The utility of an individual of skill-type $i$ is:

$$
u_{i}=c_{i}-\frac{\varepsilon}{1+\varepsilon} l_{i}^{\frac{1+\varepsilon}{\varepsilon}}+g(b)
$$

where $c_{i}$ denotes private consumption of an individual with skill-type $i, \varepsilon>0$, and $g(b)$ denotes the utility generated by the per capita public spending. We further assume that $g^{\prime}(0) \rightarrow \infty$ (an Inada condition), so that all individuals (skilled and unskilled) would like the government to levy some taxes in order to provide some positive level of $b$.

The budget constraint of an individual with skill level $i$ is:

$$
c_{i}=(1-\tau) l_{i} w_{i}
$$


Individual utility maximization yields the following labor supply equation:

$$
l_{i}=\left(w_{i}(1-\tau)\right)^{\varepsilon}
$$

It is then straightforward to calculate the equilibrium wages for the skilled and unskilled workers, which are given, respectively, by

$$
\begin{gathered}
w_{s}=A\left(\alpha \delta^{\varepsilon} \theta^{1-\alpha}\right)^{\frac{1}{1+\varepsilon}} \\
w_{u}=A\left((1-\alpha) \delta^{\varepsilon} \theta^{-\alpha}\right)^{\frac{1}{1+\varepsilon}} \\
\text { where } \delta \equiv \alpha^{\alpha}(1-\alpha)^{1-\alpha} \\
\text { and } \theta \equiv \frac{1-s+(1-\sigma) \mu}{s+\sigma \mu}
\end{gathered}
$$

In order to ensure that the skilled wage always exceeds the unskilled wage, $w_{s}>w_{u}$, we assume that

$$
\frac{\alpha(1-s)}{(1-\alpha)(s+\mu)}>1
$$

We now use this model to analyze the politico-economic choice of the welfare state variables, $\tau$ and $b$. This choice is done by majority voting. Given that there is essentially only one independent choice variable in this voting (note that once one of the variables - $\tau, b$ - is chosen, the other is determined by the budget constraint, equation (5)), the outcome of the voting is determined by the choice of the median voter.

For this purpose, note that the indirect utility of a native-born individual of skill level $i=s, u$ is given by:

$$
V_{i}(\tau ; \sigma)=g(b(\tau ; \sigma))+\frac{1}{1+\varepsilon}\left[(1-\tau) w_{i}(\sigma)\right]^{1+\varepsilon}
$$

where $\mu$ is suppressed.

Note that $w_{i}$ does not depend on $\tau$ due to the Cobb-Douglas specification of the production function; see equation (9).

An individual of a skill type $i$ opts for a tax rate $\tau_{i}$ which maximizes her utility. This tax rate is given implicitly by the first order condition

$$
\frac{\partial V_{i}}{\partial \tau}=g^{\prime}(b) \frac{\partial b}{\partial \tau}-w_{i}\left[(1-\tau) w_{i}\right]^{\varepsilon}=0
$$


for each $i=s, u$. Note also that the second-order condition is $\frac{\partial^{2} V_{i}}{\partial \tau^{2}} \leq 0$.

Because $w_{s}>w_{u}$, it follows from equation (12) that $\frac{\partial V_{u}}{\partial \tau}>0$ when $\frac{\partial V_{s}}{\partial \tau}=$ 0. Thus, as expected, an unskilled opts for a more generous welfare state (a higher tax rate, $\tau$ ) than the skilled voter. This implies that the outcome of the voting is determined by the median voter, whether skilled or unskilled.

The effect of a change in the skill composition of migrants on the generosity of the welfare state preferred by the individual of skill level $i=s, u$ is found upon total differentiation of equation (12) with respect to $\sigma$ :

$$
\frac{\partial^{2} V_{i}}{\partial \sigma \partial \tau}+\frac{\partial^{2} V_{i}}{\partial \tau^{2}} \frac{\mathrm{d} \tau}{\mathrm{d} \sigma}=0
$$

Because of the second-order condition, $\frac{\partial^{2} V_{i}}{\partial \tau^{2}} \leq 0$, it follows that

$$
\operatorname{sign}\left(\frac{\mathrm{d} \tau}{\mathrm{d} \sigma}\right)=\operatorname{sign}\left(\frac{\partial^{2} V_{i}}{\partial \sigma \partial \tau}\right)
$$

for $i=s, u$. In Appendix A we show that $\frac{\partial^{2} V_{s}}{\partial \sigma \partial \tau}>0$ and that $\frac{\partial^{2} V_{u}}{\partial \sigma \partial \tau}>0 .{ }^{7}$ Therefore, we can conclude that

$$
\frac{\mathrm{d} \tau_{i}}{\mathrm{~d} \sigma} \geq 0 \text { for both } i=s, u \text {. }
$$

That is, the two types of voters (skilled and unskilled) opt for more generous welfare state, reflected in a higher $\tau$ and $b$, when the skill composition of migration shifts more towards the skilled migrants (higher $\sigma$ ). Host countries with relatively more skilled migrants choose to have a more generous welfare system. This result follows because skilled migrants are net fiscal contributors, that is, their tax payments exceed what the welfare state spend on them. The hypothesis derived in this section is confronted with data in the next section.

\section{Empirical Evidence}

This section provides empirical evidence to the hypothesis that a higher proportion of skilled migrants has a positive effect on the welfare-state generosity

\footnotetext{
${ }^{7}$ More precisely, we show that this result holds, respectively, at the level of $\sigma$ that each skill type would have chosen, if given this option.
} 
of the host country, when this generosity is determined in majority voting (regardless of whether the median voter is skilled or unskilled).

\subsection{Econometric Model}

Assume that welfare-state per-capita spendings in country $i$ is determined according to the following equation:

$$
b_{i}=\alpha_{0}+\alpha_{s} m_{s, i}+\alpha_{u} m_{u, i}+X_{i}^{b} \beta+\epsilon_{i}^{b}
$$

where $b$ is the welfare state per-capita spendings, $m_{s}$ and $m_{u}$ denote the stocks of skilled and unskilled migrants, respectively; $X^{b}$ is a vector of other control variables and $\epsilon^{b}$ is an the error term. The respective coefficients of these variables are depicted by $\alpha_{s}, \alpha_{s}$, and $\beta$.

Note that there is an endogeneity problem concerning equation (16). It is difficult to identify the direction of causality between spendings, $b_{i}$, and migration of the two types. Indeed the $m$ 's affect $b$ as specified in this equation. But, on the other hand, the generosity of the welfare state also affects the level of migrations of the two types. Specifically, as demonstrated in Cohen and Razin (2008), the generosity of the welfare state has a negative effect on the migration of skilled individuals (who are net fiscal contributors), but a positive effect on the migration of unskilled (who are net fiscal beneficiaries), when migration is free. ${ }^{8}$

We therefore introduce instrumental variables for the two skill types of migrants. We assume that bilateral migration stocks for skill level $e=(s, u)$, between any source-host country pair $(j, i)$, are determined in accordance with the following equation:

$$
m_{e, j, i}=a_{0}+a_{1} \text { Comlang }_{j, i}+a_{2} \text { Dist }_{j, i}+X_{j, i}^{m} b+\epsilon_{j, i}^{m}, e=\{s, u\}
$$

where Comlang depicts a dummy variable, with the value 1 if the source and host countries share a common language, and 0 otherwise, Dist captures the

\footnotetext{
${ }^{8} \mathrm{An}$ additional, opposite, effect exists when the welfare state can control the volume and skill composition of migration, as between EU and non-EU countries.
} 
geographical (great circle) distance between the source-host pair, $X^{m}$ is a vector of other control variables (note that it may be pairwise specific (which further helps the identification), hence the different superscript) and $\epsilon^{m}$ is an error term.

Our identification strategy is twofold. First, the distance and common language variables (that are excluded from equation (16)) serve as instrumental variables. That is, we assume that these variables are not correlated with the error term in equation (16). On the other hand, it is quite plausible and well established that these variables affect migration, as in all gravity models. (A similar approach was first employed by Frankel and Romer (1999) who studied the effect of trade on growth.) Second, we employ a sample of EU countries (and countries who have treaties with the EU) within which there is free migration and equal treatment of native and foreign born alike. This enables us to estimate the effect of migration's skill on welfare generosity when the host country cannot take alternative measures to cope with the possible fiscal burden, as embodied within low-skill migration. ${ }^{9}$

Estimating equations (17) yields the fitted values for the bilateral skilldependent immigration stocks. We sum these fitted values across source countries:

$$
\widehat{m}_{e, i}=\sum_{j \neq i} \widehat{m}_{e, j, i}
$$

where the hat symbol denotes the fitted value estimation.

Therefore, our estimated equation is:

$$
b_{i}=\alpha_{0}+\alpha_{s} \widehat{m}_{s, i}+\alpha_{u} \widehat{m}_{u, i}+X_{i}^{b} \beta+\epsilon_{i}^{b}
$$

\footnotetext{
${ }^{9}$ When the host country can control the volume and skill composition of its immigrants, extensive welfare state spendings can be sustained by a screening migration policy which favors the skilled over the unskilled. Therefore, when facing an unskilled migration pressures, the host country can deal with that without curtailing the welfare state benefits, but simply by not allowing these migrants into the country or denying their access to some of the benefits.
} 


\subsection{Data}

Our country sample includes 16 European countries, 14 EU members (Austria, Belgium, Denmark, France, Germany, Italy, the Netherlands, Sweden, Finland, Greece, Ireland, Portugal, Spain and the U.K.), as well as Norway and Switzerland. Naturally there is free labor mobility among the (old members) EU countries. The two other countries enjoy bilateral agreements with the EU, ensuring free labor mobility. (See Cohen and Razin (2008) for detailed description of the free labor mobility treaties among countries in this sample.)

The dependent variable, $b$, is social expenditure, in cash or in kind, per capita, at constant (2000) prices, PPP converted into US\$, averaged between 2000 and 2005 (source: OECD.stat). The averaging is done in order to filter out business-cycle variations. Social expenditure encompass all kinds of social public expenditures, in cash or in kind, including, for instance, old age transfers, incapacity related benefits, health care, unemployment compensations and other social expenditures.

The stocks of migrants in either country, originated in all of the remaining countries, by education attainment, is our variables of interest. Migrants are at working age $(25+)$, defined as foreign born, subdivided into three classes of schooling years: low (0-8), medium (9-12) and high (13+). The stocks of migrants we use are lagged (1990) to further avoid possible endogeneity problem (source: Docquier and Marfouk (2006)).

We control for the domestic labor force for each skill level in each country in 2000 (source: Docquier and Marfouk (2006)). This control variable is essential in light of the fact that we employ the number of migrants rather than their proportions as the variable of interest. It also captures the relative power of the different interests groups, as manifested in the politico-economic equilibrium, and the effect of migration on wages. Additionally, we include GDP per capita, PPP adjusted to US\$ in constant prices (2000), averaged 
between 2000 and 2004 (source: Penn World Tables 6.2). Normally, as a country's production is higher, its ability to dispense welfare-state per-capita spendings is higher. Given that the GDP per capita is potentially correlated with migration stocks, as potential income measure, its inclusion is necessary. We also control for old age $(65+)$ share in the population, averaged between 2000 and 2007 (source: U.S. Census Bureau, International). Pension benefits captures a vast portion of the welfare-state spending; thus, this variable should be highly positively correlated with the dependent variable, and therefore should be included as a control variable. ${ }^{10}$

\subsection{Results}

The results of the regression are described in Table (1):

\begin{tabular}{|l|c|c|}
\hline \multicolumn{3}{|c|}{ Dependent variable: benefits per capita (2000-2005) } \\
\hline & OLS & 2SLS \\
\hline High skilled migrants (1990) & -17.532 & 45.506 \\
& $(8.348)^{*}$ & $(17.015)^{* *}$ \\
Low skilled migrants (1990) & 1.866 & -7.011 \\
& $(0.245)^{* * *}$ & $(2.627)^{* *}$ \\
\hline GDP per capita (2000-2004) & 368.13 & 433.613 \\
& $(58.054)^{* * *}$ & $(84.725)^{* * *}$ \\
Old age share (2000-2007) & 521.675 & 557.530 \\
& $(137.087)^{* * *}$ & $(108.549)^{* * *}$ \\
Domestic high-skilled (2000) & 0.045 & -0.401 \\
& -0.109 & $(0.178)^{*}$ \\
Domestic low-skilled (2000) & -0.053 & 0.068 \\
& $(0.015)^{* * *}$ & $(0.040)$ \\
\hline Observations & 16 & 16 \\
R-squared & 0.884 & 0.836 \\
\hline all variables are in thousands, except for Old age share (in \%) \\
Robust standard errors in parentheses \\
2SLS uses distance and common language as IV \\
* significant at 10\%; ** significant at 5\%; *** significant at 1\% \\
\hline
\end{tabular}

Table 1: The effect of Skill Composition of Migrants on Welfare-State Spendings

Consider first the first column. Migrants with high (low) education level

\footnotetext{
${ }^{10}$ Given the small number of observations (16), we must focus on the two variables of interests $\left(\widehat{m}_{s, i}\right.$ and $\left.\widehat{m}_{u, i}\right)$ and employ only the few most important exogenous control variables.
} 
have a negative (positive) effect on the welfare-state spendings in the host countries. This result could be due to reverse causality (despite the lagging of migration stocks): higher spendings reduce the skill composition of migration in free migration regimes (Cohen and Razin (2008)).

The second column employs the fitted migration stocks from the first stage regression (equation (17)). The result is exactly opposite: high (low) skilled migrants have a positive (negative) effect on the level of welfare state spendings. This is in line with the conclusions of our parsimonious model. Host country adopts a more generous welfare system when high-skill migrants (who are net fiscal contributors) enter the country. The opposite applies in the case of low-skill migration: the host country is reluctant to increase its welfare generosity when such migrants (who are net fiscal beneficiaries) arrive.

\subsection{Robustness}

We check the robustness of our results in several manners. First, we replace the skill composition of the migrants. We commence by exploring the effect of medium-skill (high school education) and low-skill (elementary school education) migrants on the welfare generosity of their host country. Then we combine the medium- and low-skill migrants into one group versus the high skilled (above high school education). The results are very similar to our main findings above (see Tables 2 and 3 in Appendix B).

Secondly, we replace the dependent variable. Instead of using the average between 2000 and 2005, we use averages in broader periods (1995-2005, 19902005, 1985-2005 and 1980-2005). Alternatively, we use a different measure for governmental spending on welfare: we take the average tax rate and multiply it by the GDP per capita, yielding thereby a measure of the average tax revenues per capita. From this measure we subtract the product of defense expenses as percentage of the GDP and the GDP per capita (which yields a measure of the defense expenses per capita). All the results are consistent 
with our primary finding. That is, when employing the instrumental variable estimation, high-skill migrants induce enlargement of the welfare state (as opposed to OLS estimation which captures the reverse causality); low-skill migrants induce the reduction of the welfare state, although not all results are as statistically significant as in the main estimation (see Tables 4,5 and 6 in Appendix B)

Thirdly, we use different specifications of the estimated model (equation (19)). We start by incorporating the Gini coefficient (before tax-transfers). This measure of inequality is expected to be positively correlated with the generosity of the welfare state. We then account for cultural affinity towards welfare and social rights, by using the legal origin of the countries. Countries whose legal origin is English (like the U.K. or Ireland) are traditionally more protective of property rights than social rights, relatively to countries with French-German origin, or Scandinavian origin. Finally, we control for unemployment rates of the host countries. We expect the unemployment rate to be positively correlated with the measure of welfare spending. All results further validate our hypothesis (see Tables 7, 8 and 9 in Appendix B).

\section{Conclusion}

Skilled migrants typically contribute to the welfare state more than they draw in benefits from it. The opposite holds for unskilled migrants. This suggests that a host country is likely to boost (respectively, curtail) its welfare system when absorbing high-skill (respectively, low-skill) migration. In this paper we examined this hypothesis. We first constructed a parsimonious politico-economic model. We showed that indeed a higher proportion of skilled migration for a given volume of migration encourages a host country to opt for a more generous welfare state system. We then confronted this prediction with evidence from EU countries. In doing so, we reckon with an endogeneity problem that arise because the skill composition of migration is 
itself affected by the generosity of the welfare state. We indeed found that the evidence supports the prediction of the theory. Furthermore, if one ignores this endogeneity problem (and employs OLS estimation) the estimates of the effects of the skilled and unskilled migration on the generosity of the welfare state are severely biased, so much so as to reverse the direction of these effects.

We conjecture that in the same parsimonious model a brain drain from the source country will push it towards curtailing the extent of its welfare system. A useful direction for future research is to confront this hypothesis with evidence.

\section{References}

[1] Auerbach, A. and P. Oreopoulos (1999), "Analyzing the Fiscal Impact of U.S. Immigration", American Economic Review, Papers and Proceedings 89 (May), 176-180.

[2] Cohen, Alon and Assaf Razin (2008), "The Skill Composition of Immigrants and the Generosity of the Welfare state: Free versus PolicyControlled Migration", NBER Working Paper 14459, October.

[3] Docquier, Frederic and Abdeslam Marfouk (2006), "International Migration by Educational Attainment (1990-2000)", in Ozden, Caglar and Maurice Schiff (eds.), International Migration, Remittances and the Brain Drain, McMillan and Parlgrave: New York.

[4] Frankel, Jeffrey A. and David Romer (1999), "Does Trade Cause Growth?", American Economic Review, 89(2) June, 379-399.

[5] Hanson, Gordon H. (2008), "The Economic Consequences of the International Migration of Labor", NBER Working Paper 14490, November. 
[6] Razin, Assaf and Efraim Sadka (2004), "Welfare Migration: Is the Net Fiscal Burden a Good Measure of its Economic Impact on the Welfare of the Native-Born Population?" CESifo Economic Studies, 50(4), 709-716.

[7] Razin, Assaf, Efraim Sadka and Phillip Swagel (2002), "Tax Burden and Migration: A Political Theory and Evidence", Journal of Public Economics, 85, 167.

[8] Smith, James P. and Barry Edmonston, editors (1997), The new American: Economic, Demographic and Fiscal effects of Immigration, National academy Press, Washington, D.C.

[9] Storesletten, K. (2000), "Sustaining fiscal policy through immigration", The Journal of Political Economy 108, 300-323. 


\section{A Proof}

Differentiating equation (12) with respect to $\sigma$, we get:

$$
\frac{\partial^{2} V_{i}}{\partial \tau \partial \sigma}=\left[g^{\prime \prime}(b)+g^{\prime}(b)\right] \frac{\partial^{2} b}{\partial \sigma \partial \tau}+\frac{\partial}{\partial \tau}\left[(1-\tau)\left[(1-\tau) w_{i}\right]^{\varepsilon} \frac{\partial w_{i}}{\partial \sigma}\right]
$$

In Cohen and Razin (2008) it is shown that when $g$ is linear (more precisely, $g^{\prime}=1$ and $g^{\prime \prime}=0$ ), then the expression in equation (20) is positive in the vicinity of $\partial V_{i} / \partial \sigma=0$; that is at the level of $\sigma$ most preferred by an individual of skill level $i=s, u$. In fact, the reason why we made $g$ nonlinear with $g^{\prime}(0) \rightarrow \infty$ is to ensure that all skill types would prefer a positive level of government spending (an Inada condition). But it is quite plausible to make $g$ approximately linear beyond a very small level of $b$ and that $b$ is perfectly substitutable to private consumption (that is, $g^{\prime}=1$ and $g^{\prime \prime}=0$ ).

In this case, indeed $\frac{\partial^{2} V_{i}}{\partial \tau \partial \sigma}>0$.

\section{B Tables}




\begin{tabular}{|l|c|c|}
\hline \multicolumn{3}{|c|}{ Dependent variable: benefits per capita (2000-2005) } \\
\hline High skilled migrants (1990) & OLS & 2SLS \\
\hline Low skilled migrants (1990) & $(3.085)^{*}$ & 26.325 \\
& 1.210 & $-7.781)^{*}$ \\
& $(0.188)^{* * *}$ & $(3.541)^{*}$ \\
\hline GDP per capita (2000-2004) & 379.862 & 410.406 \\
& $(63.505)^{* * *}$ & $(82.132)^{* * *}$ \\
Old age share (2000-2007) & 581.111 & 399.920 \\
& $(120.049)^{* * *}$ & $(112.922)^{* * *}$ \\
Domestic med-skilled (2000) & -0.024 & -0.063 \\
Domestic low-skilled (2000) & $(0.018)$ & $(0.028)^{* *}$ \\
& -0.047 & 0.073 \\
& $(0.018)^{* *}$ & $(0.056)$ \\
\hline Observations & 16 & 16 \\
R-squared & 0.889 & 0.834 \\
\hline all variables are in thousands, except for Old age share (in \%) \\
Robust standard errors in parentheses \\
2SLS uses distance and common language as IV \\
* significant at 10\%; ** significant at 5\%;** significant at 1\% \\
\hline
\end{tabular}

Table 2: Robustness: Medium- vs. Low-skilled

\begin{tabular}{|l|c|c|}
\hline \multicolumn{3}{|c|}{ Dependent variable: benefits per capita (2000-2005) } \\
\hline & OLS & 2SLS \\
\hline High skilled migrants (1990) & -21.768 & 49.632 \\
Medium-Low skilled migrants (1990) & $(9.080)^{* *}$ & $(17.571)^{* *}$ \\
& 1.869 & -6.094 \\
& $(0.398)^{* * *}$ & $(2.294)^{* *}$ \\
\hline GDP per capita (2000-2004) & 365.327 & 433.934 \\
& $(56.684)^{* * *}$ & $(85.087)^{* * *}$ \\
Old age share (2000-2007) & 503.101 & 593.742 \\
& $(143.144)^{* * *}$ & $(114.168)^{* * *}$ \\
Domestic med-skilled (2000) & 0.077 & -0.404 \\
& $(0.115)$ & $(0.177)^{* *}$ \\
Domestic low-skilled (2000) & -0.054 & 0.053 \\
& $(0.016)^{* * *}$ & $(0.036)$ \\
\hline Observations & 16 & 16 \\
R-squared & 0.878 & 0.836 \\
\hline all variables are in thousands, except for Old age share (in \%) \\
Robust standard errors in parentheses \\
2SLS uses distance and common language as IV \\
* significant at 10\%; ** significant at 5\%; *** significant at 1\% \\
\hline
\end{tabular}

Table 3: Robustness: High vs. Medium-low-skilled 


\begin{tabular}{|l|c|c|c|c|}
\hline \multicolumn{4}{|c|}{ Dependent variable: benefits per capita } \\
\hline & \multicolumn{2}{|c|}{ 1995-2005 } & \multicolumn{2}{c|}{ 1990-2005 } \\
\hline & OLS & 2SLS & OLS & 2SLS \\
\hline High skilled migrants (1990) & -16.667 & 47.365 & -14.530 & 44.525 \\
& $(9.442)$ & $(18.534)^{* *}$ & $(11.335)$ & $(20.411)^{*}$ \\
Low skilled migrants (1990) & 1.980 & -6.672 & 1.946 & -6.043 \\
& $(0.283)^{* * *}$ & $(3.030)^{*}$ & $(0.339)^{* * *}$ & $(3.763)$ \\
\hline GDP per capita (2000-2004) & 374.372 & 427.927 & 360.927 & 407.284 \\
& $(63.088)^{* * *}$ & $(92.659)^{* * *}$ & $(70.980)^{* * *}$ & $(113.945)^{* * *}$ \\
Old age share (2000-2007) & 557.052 & 593.406 & 559.026 & 586.002 \\
& $(151.257)^{* * *}$ & $(132.101)^{* * *}$ & $(179.440)^{* *}$ & $(159.413)^{* * *}$ \\
Domestic high-skilled (2000) & 0.035 & -0.417 & 0.014 & -0.394 \\
& $(0.117)$ & $(0.191)^{*}$ & $(0.139)$ & $(0.206)^{*}$ \\
Domestic low-skilled (2000) & -0.056 & 0.059 & -0.057 & 0.049 \\
& $(0.016)^{* * *}$ & $(0.048)$ & $(0.019)^{* *}$ & $(0.059)$ \\
\hline Observations & 16 & 16 & 16 & 16 \\
R-squared & 0.867 & 0.819 & 0.817 & 0.774 \\
\hline all variables are in thousands, except for Old age share (in \%) & & \\
Robust standard errors in parentheses & & & \\
2SLS uses distance and common language as IV & & & \\
* significant at 10\%; ** significant at 5\%;*** significant at $1 \%$ & & & \\
\hline
\end{tabular}

Table 4: Robustness: Different Average of the Benefits

\begin{tabular}{|l|c|c|c|c|}
\hline \multicolumn{4}{|c|}{ Dependent variable: benefits per capita } \\
\hline & \multicolumn{2}{|c|}{ 1985-2005 } & \multicolumn{2}{c|}{ 1980-2005 } \\
\hline & OLS & 2SLS & OLS & 2SLS \\
\hline High skilled migrants (1990) & -13.401 & 42.919 & -12.181 & 39.637 \\
& $(11.831)$ & $(20.596)^{*}$ & $(12.193)$ & $(20.467)^{*}$ \\
Low skilled migrants (1990) & 1.911 & -5.625 & 1.788 & -4.850 \\
& $(0.332)^{* * *}$ & $(3.906)$ & $(0.326)^{* * *}$ & $(3.942)$ \\
\hline GDP per capita (2000-2004) & 359.515 & 399.841 & 358.796 & 386.988 \\
& $(71.559)^{* * *}$ & $(117.620)^{* * *}$ & $(66.613)^{* * *}$ & $(112.629)^{* * *}$ \\
Old age share (2000-2007) & 553.145 & 577.039 & 547.650 & 572.696 \\
Domestic high-skilled (2000) & $(177.261)^{* *}$ & $(157.583)^{* * *}$ & $(173.751)^{* *}$ & $(155.899)^{* * *}$ \\
& -0.008 & -0.395 & -0.021 & -0.379 \\
Domestic low-skilled (2000) & $(0.147)$ & $(0.207)^{*}$ & $(0.151)$ & $(0.206)^{*}$ \\
& -0.054 & 0.045 & -0.052 & 0.033 \\
\hline Observations & $(0.018)^{* *}$ & $(0.062)$ & $(0.016)^{* * *}$ & $(0.064)$ \\
R-squared & 16 & 16 & 16 & 16 \\
\hline all variables are in thousands, except for Old age share (in \%) & & & 0.782 \\
Robust standard errors in parentheses & & & \\
2SLS uses distance and common language as IV & & & \\
* significant at 10\%; ** significant at 5\%;** significant at 1\% & & & \\
\hline
\end{tabular}

Table 5: Robustness: Different Measure of the Benefits 


\begin{tabular}{|l|c|c|}
\hline \multicolumn{3}{|c|}{ Dependent variable: GDPp * (tax rate - defense pc) } \\
\hline High skilled migrants (1990) & OLS & 2SLS \\
\hline Low skilled migrants (1990) & $(39.165)$ & 105.361 \\
& 2.562 & $(45.259)^{* *}$ \\
& $(1.622)$ & $(6.543)$ \\
\hline GDP per capita (2000-2004) & 509.746 & 389.185 \\
& $(116.065)^{* * *}$ & $(168.228)^{* *}$ \\
Old age share (2000-2007) & 391.386 & 511.042 \\
& $(244.199)$ & $(305.853)$ \\
Domestic high-skilled (2000) & -0.298 & -1.096 \\
& $(0.371)$ & $(0.460)^{* *}$ \\
Domestic low-skilled (2000) & -0.047 & 0.009 \\
& $(0.060)$ & $(0.079)$ \\
\hline Observations & 15 & 15 \\
R-squared & 0.728 & 0.847 \\
\hline all variables are in thousands, except for Old age share (in \%) \\
Robust standard errors in parentheses \\
2SLS uses distance and common language as IV \\
* significant at 10\%; ** significant at 5\%; *** significant at 1\% \\
\hline
\end{tabular}

Table 6: Robustness: Different Measure of the Benefits

\begin{tabular}{|l|c|c|}
\hline \multicolumn{3}{|c|}{ Dependent variable: benefits per capita (2000-2005) } \\
\hline & OLS & 2 SLS \\
\hline High skilled migrants (1990) & -18.807 & 49.465 \\
& $(9.144)^{*}$ & $(15.954)^{* *}$ \\
Low skilled migrants (1990) & 1.916 & -7.059 \\
& $(0.303)^{* * *}$ & $(2.630)^{* *}$ \\
\hline GDP per capita (2000-2004) & 366.775 & 418.696 \\
& $(58.073)^{* * *}$ & $(88.375)^{* * *}$ \\
Old age share (2000-2007) & 533.445 & 427.161 \\
& $(150.391)^{* * *}$ & $(119.470)^{* * *}$ \\
Domestic high-skilled (2000) & 0.063 & -0.481 \\
& $(0.119)$ & $(0.174)^{* *}$ \\
Domestic low-skilled (2000) & -0.053 & 0.053 \\
Gini (before tax-transfer) (mid 2000) & $(0.018)^{* *}$ & $(0.036)$ \\
& -19.014 & 167.181 \\
\hline Observations & $(26.107)$ & $(64.795)^{* *}$ \\
R-squared & 16 & 16 \\
\hline all variables are in thousands, except for Old age share (in \%) & \\
Robust standard errors in parentheses & 0.888 & 0.846 \\
2SLS uses distance and common language as IV & \\
* significant at 10\%; $* *$ significant at 5\%; *** significant at $1 \%$ \\
\hline
\end{tabular}

Table 7: Robustness: Including Gini Coefficient 


\begin{tabular}{|l|c|c|}
\hline \multicolumn{3}{|c|}{ Dependent variable: benefits per capita (2000-2005) } \\
\hline High skilled migrants (1990) & OLS & 2SLS \\
\hline Low skilled migrants (1990) & $(9.671)$ & $(16.883)^{* * *}$ \\
& 1.741 & -5.283 \\
& $(0.528)^{* *}$ & $(2.527)^{*}$ \\
\hline GDP per capita (2000-2004) & 321.299 & 257.661 \\
Old age share (2000-2007) & $(75.802)^{* * *}$ & $(143.321)$ \\
& 457.474 & 401.993 \\
Domestic high-skilled (2000) & $(194.730)^{*}$ & $(134.737)^{* *}$ \\
& 0.030 & -0.482 \\
Domestic low-skilled (2000) & $(0.097)$ & $(0.146)^{* *}$ \\
& -0.038 & 0.033 \\
English legal origin & $(0.019)^{*}$ & $(0.024)$ \\
& -81.775 & $-1,779.475$ \\
Scandinavian legal origin & $(708.103)$ & $(571.628)^{* *}$ \\
& 812.909 & $1,008.628$ \\
& $(601.369)$ & $(1,235.552)$ \\
\hline Observations & 16 & 16 \\
R-squared & 0.913 & 0.901 \\
\hline all variables are in thousands, except for Old age share (in \%) \\
Robust standard errors in parentheses & \\
Benchmark legal origin is French-German & \\
2SLS uses distance and common language as IV \\
* significant at 10\%; ** significant at 5\%;** significant at 1\% \\
\hline
\end{tabular}

Table 8: Robustness: Adding Legal Origin

\begin{tabular}{|l|c|c|}
\hline \multicolumn{3}{|c|}{ Dependent variable: benefits per capita (2000-2005) } \\
\hline & OLS & 2SLS \\
\hline High skilled migrants (1990) & -14.948 & 48.865 \\
& $(9.521)$ & $(18.134)^{* *}$ \\
Low skilled migrants (1990) & 1.998 & -5.921 \\
& $(0.375)^{* * *}$ & $(3.233)$ \\
\hline GDP per capita (2000-2004) & 387.402 & 474.927 \\
& $(61.117)^{* * *}$ & $(98.614)^{* * *}$ \\
Old age share (2000-2007) & 592.595 & 717.591 \\
& $(187.959)^{* *}$ & $(124.663)^{* * *}$ \\
Domestic high-skilled (2000) & 0.003 & -0.473 \\
& $(0.128)$ & $(0.175)^{* *}$ \\
Domestic low-skilled (2000) & -0.069 & 0.023 \\
& $(0.026)^{* *}$ & $(0.052)$ \\
Unemployment (1990-1999) & 71.235 & 231.502 \\
& $(72.151)$ & $(82.683)^{* *}$ \\
\hline Observations & 16 & 16 \\
R-squared & 0.894 & 0.847 \\
\hline all variables are in thousands, except for Old age share (in \%) \\
Robust standard errors in parentheses \\
2SLS uses distance and common language as IV \\
* significant at 10\%; ** significant at 5\%;*** significant at 1\% \\
\hline
\end{tabular}

Table 9: Robustness: Adding Unemployment 